\title{
POLIMORFISMO ENZIMÁTICO NOS TECIDOS DE PEREIRA ${ }^{1}$
}

\author{
JOSÉ CARLOS FACHINELLO ${ }^{2}$, STEFANO MUSACCHI ${ }^{3}$, SILVIAZUCCHERELLI ${ }^{3}$ e SILVIERO SANSAVINI ${ }^{4}$
}

RESUMO - O trabalho foi realizado com o objetivo de avaliar o polimorfismo enzimático em diferentes tecidos de oito cultivares de pereira Pyrus communis L. Os genótipos utilizados fazem parte da coleção de plantas disponíveis na Universidade de Estudos de Bolonha. Para as análises isoenzimáticas foram utilizadas gemas floríferas dormentes no inverno, casca de ramos de um ano obtida de plantas em pleno desenvolvimento, folhas obtidas no início da primavera e folhas de plantas mantidas in vitro. A corrida eletroforética foi realizada em gel de poliacrilamida a gradiente com $(5 \%$ a $12,5 \%)$. Os resultados obtidos com os genótipos utilizados indicaram que o sistema enzimático $\beta$-glucosidase (E.C.3.2.1.21) apresentou atividade apenas nas folhas das plantas in vitro, com uma banda na mesma posição para todas as cultivares, ao passo que os sistemas para as enzimas esterase (E.C.3.1.1.2) e peroxidase (E.C.1.11.1.7) apresentaram elevado polimorfismo. Nas gemas dormentes analisadas, o sistema peroxidase permitiu diferenciar todos os genótipos. As formas isoenzimáticas da esterase permitiram separar todos os genótipos independentemente dos tecidos utilizados.

Termos para indexação: Pyrus communis, polimorfismo enzimático, esterase, peroxidase, beta glucosidase.

\section{ISOENZYMATIC VARIABILITY IN PEAR TISSUES FOR FINGERPRINTING}

\begin{abstract}
Eight self-rooted genotype of pear (Pyrus communis L.) were assessed to assert the patterns of the isoenzymatic systems $\beta$-glucosidase (E.C.3.2.1.21), esterase (E.C.3.1.1.2) and peroxidase (E.C.1.11.1.7). Tissues samples of buds, leaves, shoot bark and in vitro leaves were analyzed by polyacrylamide gel electrophoresis (5\% to $12.5 \%$ ). High variability of esterase isoenzyme was detected among the tissues of each cultivar. The $\beta$-glucosidase activity was detected only in in vitro leaves, otherwise polymorphism was not found. High variability of peroxidase in all pear genotypes was found with isoenzyme extract from buds. The other tissues showed enough variability, although less variability was detected for differentiation of all assayed cultivars. Esterase proved to be most reliable enzyme for identification of pear cultivars and in the other two were less effective in all the tissues tested.
\end{abstract}

Index terms: Pyrus communis, enzyme polymorphism, esterases, peroxidases, beta glucosidase.

\section{INTRODUÇÃo}

A caracterização de plantas frutíferas lenhosas mediante o uso de marcadores genéticos é uma

\footnotetext{
${ }^{1}$ Aceito para publicação em 20 de julho de 1999

${ }^{2}$ Eng. Agrôn., Dr., Prof. Titular, Dep. de Fitotecnia, Faculdade de Agronomia Eliseu Maciel (FAEM), Universidade Federal de Pelotas (UFPEL), Caixa Postal 354, CEP 96001-970 Pelotas, RS. Bolsista da Capes. E-mail: jfachi@ufpel.tche.br

${ }^{3}$ Eng. Agrôn., Dr., Dipartimento di Colture Arboree, Università Degli Studi di Bologna, Via Filippo Re 6 - 40126 Bologna, Italia.

${ }^{4}$ Eng. Agrôn., Dr., Prof. Titular, Dipartimento di Colture Arboree, Università Degli Studi di Bologna.
}

prática de uso comum para fins de melhoramento genético e identificação varietal, técnica que auxilia os viveiristas e detentores de patentes varietais a dirimir dúvidas sobre a qualidade genética do material em uso.

A identificação das cultivares por meio do seu fenótipo enzimático é um método rápido e eficiente e pode ser utilizado em plantas frutíferas com sucesso, conforme os resultados obtidos por Torres \& Berg (1980) em abacateiro; Anagnostakis (1991) em castanheira; Durhan et al. (1987) e Ibanez et al. (1993) em pessegueiro e nectarineira; Weeden \& Lamb (1985), Vinterhalter \& James (1986b) e Manganaris \& Alston (1993) em macieira; Menendez \& Daley (1986) em pereira; Hudina et al. (1996) em pereira e marmeleiro. 
Os trabalhos desenvolvidos por Santamour Junior $\&$ Demuth (1980), na cultura da pereira, com as formas isoenzimáticas da peroxidase permitiram identificar as cultivares do grupo caleriana (Pyrus calleryana Desc.), já os trabalhos desenvolvidos por Daley et al. (1987) permitiram diferenciar todas as cultivares de pereira (Pyrus communis L.), com exceção das mutantes de cor vermelha.

O padrão isoenzimático pode variar em função de muitos fatores, entre eles, os tecidos da planta, estádio fenológico, espécie, sanidade da planta, cultivar, porta-enxerto. Trabalho desenvolvido por Cerezo \& Socias (1989) com pólen de pereira permitiu identificar as diferentes cultivares com mais de um sistema enzimático. Os experimentos conduzidos por Hudina et al. (1996), com as enzimas esterase, peroxidase e malato desidrogenase, em diversos tecidos de plantas de pereira e marmeleiro permitiram concluir que os melhores resultados foram obtidos de gemas dormentes e que a enzima esterase foi a que se mostrou mais favorável à identificação das cultivares.

Este trabalho foi realizado com o objetivo de verificar a variabilidade isoenzimática em diferentes tecidos de pereira, incluindo tecidos in vitro, para utilização na identificação varietal nessa espécie.

\section{MATERIAL E MÉTODOS}

O trabalho foi desenvolvido no Departamento de Culturas Arbóreas da Universidade de Bolonha, Itália, e os genótipos de pereira utilizados para as análises enzimáticas fazem parte das coleções de plantas disponíveis na própria universidade.

Os tecidos foram obtidos de plantas auto-radicadas das cultivares Williams, Butirra Hardy, Kaiser, Abate de Fétel, Decama del Comizio, Passa Crassana, Conference, Packam's Triumph, com sete anos, e de plantas das cultivares Conference, Abate Fétel, Decana del Comizio, Butirra Hardy e Kaiser mantidas in vitro.

Para as análises isoenzimáticas, foram utilizadas gemas floríferas dormentes no inverno, casca do ramo de um ano de plantas em pleno desenvolvimento, folhas obtidas no início da primavera e folhas de plantas mantidas in vitro.

A extração das enzimas foi feita com o protocolo de Vallejos (1983) modificado, mediante maceração das amostras na presença de nitrogênio líquido a $-80^{\circ} \mathrm{C}$ e seguida da adição de $4 \mu \mathrm{L}$ da solução tampão $(50 \mathrm{~mL}$ de Tris-HCl 0,1 M pH 7,5; $500 \mathrm{mg}$ de polietileno glicol (PEG 6000); $25 \mathrm{mg}$ de ditiotreitol (DDT); $500 \mathrm{mg}$ de polivinilpolipirrolidona (PVPP); $3 \mathrm{~g}$ de sacarose; $50 \mu \mathrm{L}$ de mercaptoetanol e $0,15 \%$ de ácido L-ascórbico), para cada miligrama do material, cuja proporção para os tecidos in vitro foi de $1: 1$, homogeneizadas e centrifugadas por uma hora a $13.000 \mathrm{rpm}$ a $4{ }^{\circ} \mathrm{C}$.

O sobrenadante foi repartido em alíquotas de $50 \mu \mathrm{L}$ e armazenado a $-80^{\circ} \mathrm{C}$ até a sua utilização. A eletroforese realizada foi do tipo vertical utilizando-se gel de poliacrilamida com gradiente de $5 \%$ a $12,5 \%$ em temperatura $4^{\circ} \mathrm{C}$, com equipamento da Biorad (Protean II); para a esterase foi realizada uma pré-corrida de 45 minutos a $100 \mathrm{~V}$ e migração de 5 horas a $350 \mathrm{~V}$; e para a peroxidase e $\beta$-glucosidase, migração de 16 horas a $150 \mathrm{~V}$, com amostras de $50 \mu \mathrm{L}$ misturadas com $5 \mu \mathrm{L}$ de bromofenol. O tampão do eletrólito utilizado foi o Tris-borato $\mathrm{pH} 8,3$ (Tris, 109 g, ácido bórico, 56 g, ácido acético tetradiaminoetileno (EDTA), 9 g, em um litro de água) na proporção de 1:10, ou seja, uma parte da solução para 10 de água

Para a resolução dos sistemas enzimáticos foram adotados os seguintes procedimentos: a) $\beta$-glucosidase: para detectar a atividade dessa enzima o gel foi colocado para reagir de acordo com a solução proposta por Stuber et al. (1977) modificado, ou seja, $90 \mathrm{~mL}$ de tampão fosfato de sódio $0,1 \mathrm{M} \mathrm{pH} \mathrm{6,5,100} \mathrm{mg} \mathrm{de} \mathrm{"Fast} \mathrm{blue} \mathrm{BB} \mathrm{salt",}$ $50 \mathrm{mg}$ de 6-bromo-2-naftil- $\beta$-D-glucopiranoside. O substrato foi dissolvido em $10 \mathrm{~mL}$ de dimetil sulfóxido (DMSO) e vertido sobre o gel junto com a solução. Os géis foram incubados em estufa a $37^{\circ} \mathrm{C}$ por um período de três horas, até o surgimento das bandas. Depois da revelação, os géis foram lavados duas vezes com água destilada, fixados em ácido acético 7\%, fotografados e secados durante duas horas sob ventilação entre duas folhas de gel de celofane; b) Peroxidase: para detectar a atividade dessa enzima o gel foi colocado para reagir de acordo com a técnica proposta por Vinterhalter \& James (1986a), ou seja, na presença de $70 \mathrm{~mL}$ do tampão acetato de sódio $\mathrm{pH} 5,0$ a $0,1 \mathrm{M}$, $100 \mathrm{mg}$ de O-dianisidina, $30 \mu \mathrm{L}$ de etanol e $300 \mathrm{~mL}$ de peróxido de hidrogênio. A O-dianisidina foi dissolvida no etanol e depois misturada no tampão. O peróxido de hidrogênio foi adicionado na solução reveladora no momento de verter sobre o gel. A incubação se deu em torno de três a quatro minutos. Após a revelação, o gel foi lavado duas vezes com água destilada e fixado com etanol e água destilada na proporção de 1:1, fotografado e secado entre folhas de celofane de gelatina por duas horas; c) Esterase: para detectar a presença de esterases nas amostras utilizou-se o 
protocolo de Scandalios (1969) modificado, contendo

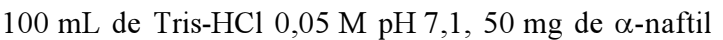
acetato, $50 \mathrm{mg}$ de $\beta$-naftil acetato e $100 \mathrm{mg}$ de "Fast Blue RR". Os substratos foram dissolvidos em $2 \mathrm{~mL}$ de etanol e misturados na solução pouco antes de serem derramados sobre o gel. A incubação foi feita por 25 minutos no escuro a $30-35^{\circ} \mathrm{C}$. Em seguida, o gel foi lavado duas vezes em água destilada, fotografado e colocado para secar.

A representação dos zimogramas é baseada na mobilidade relativa das enzimas, conforme Manganaris \& Alston (1993).

\section{RESULTADOS E DISCUSSÃO}

Os resultados obtidos com os géis para a enzima $\beta$-glucosidase (E.C.3.2.1.21), nas gemas, folhas e casca dos ramos de pereira não mostraram nenhuma banda eletroforética, entretanto foi encontrada apenas uma banda, na mesma posição, nas folhas de todas as plantas cultivadas in vitro. Esses resultados indicam que o método utilizado não permitiu revelar a presença da enzima nos tecidos de pereira cultivadas no campo. Isso pode ser atribuído à baixa atividade enzimática da $\beta$-glucosidase nas gemas, folhas e casca dos ramos das plantas a campo ou a necessidade de otimizar a extração enzimática, visto que os tecidos de pereira apresentam elevados níveis de compostos fenólicos que aceleram o processo de oxidação do extrato enzimático. O mesmo não aconteceu com os tecidos in vitro, cuja quantidade de fenóis é baixa. Segundo os experimentos realizados por Stuber et al. (1977), a enzima $\beta$-glucosidase apresenta elevado polimorfismo em outras espécies vegetais, tais como o milho, mas não na pereira com o uso da mesma metodologia.

Em relação à enzima peroxidase (E.C.1.11.1.7), verificou-se existência de polimorfismo nos tecidos utilizados, permitindo que os genótipos fossem diferenciados pela variabilidade isoenzimática. Com as folhas (Fig. 1), o polimorfismo possibilitou separar as cultivares Butirra Hardy, Kaiser e Williams das cultivares Abate Fétel, Conference, Decana del Comizio, Packham's Triumph e Passa Crassana. As gemas floríferas (Fig. 2) foram os tecidos com a maior fonte de variação, pois permitiram que todos os genótipos utilizados fossem separados com base no polimorfismo enzimático. Comparada com as fo-

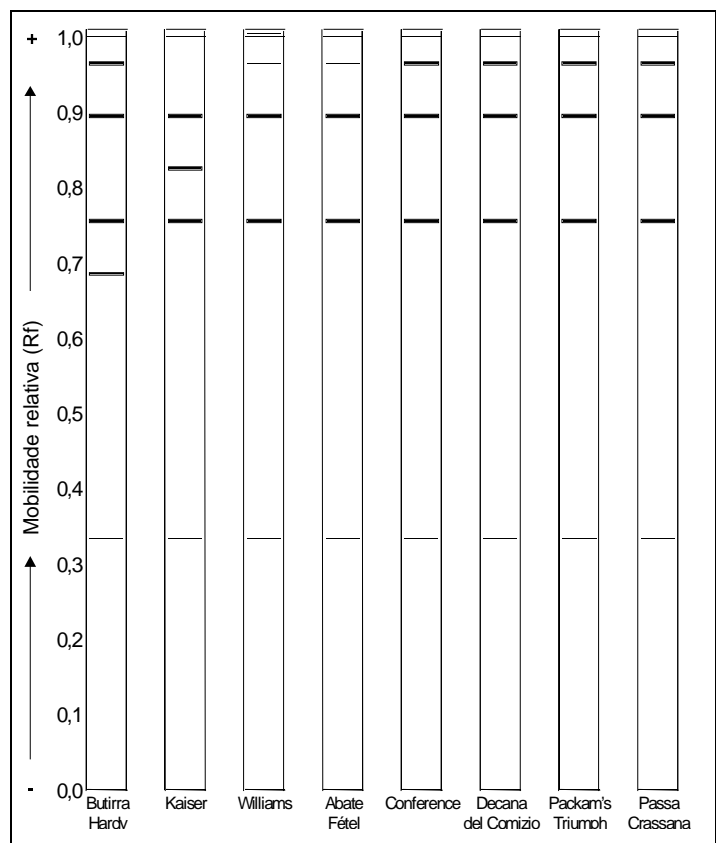

FIG. 1. Padrão isoenzimático da peroxidase obtido nas folhas de oito genótipos de pereira autoradicadas. Bolonha, Itália, 1998.

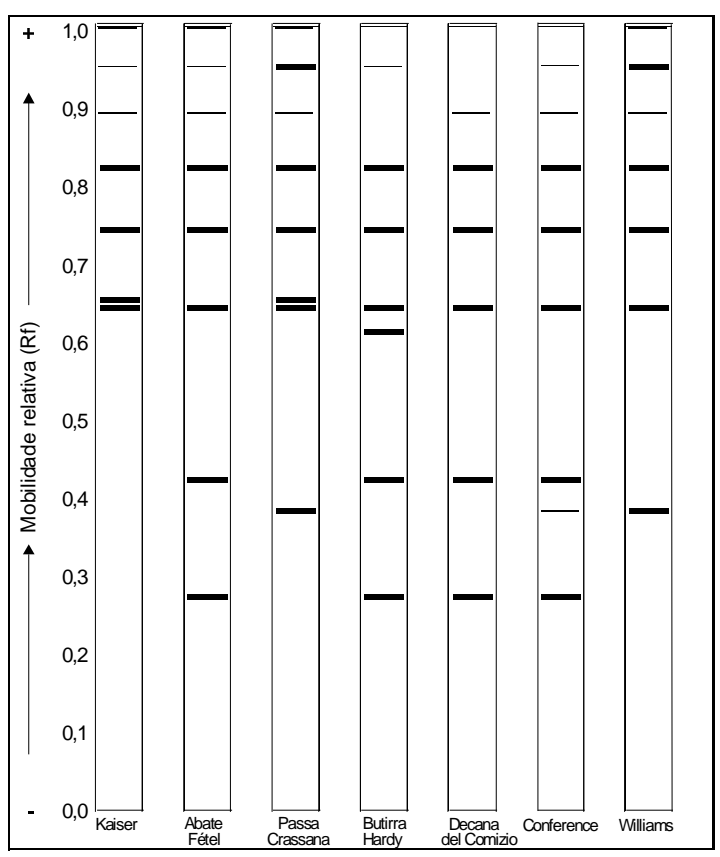

FIG. 2. Padrão isoenzimático da peroxidase obtido das gemas floríferas dormentes de oito genótipos de pereira auto-radicadas. Bolonha, Itália, 1998. 
lhas, a casca de ramos (Fig. 3) apresentou maior variabilidade, e apenas as cultivares Abate Fétel, Conference e Decana del Comizio apresentaram o mesmo fenótipo enzimático. Nos tecidos das plantas in vitro (Fig. 4), apenas as cultivares Abate Fétel e Decana del Comizio apresentavam o mesmo fenótipo isoenzimático. Tais resultados são semelhantes aos obtidos por Hudina et al. (1996) em diferentes cultivares de pereira e marmeleiro. A menor variabilidade foi verificada nas folhas, o que é atribuído à elevada quantidade de fenóis que compromete a qualidade do extrato enzimático e acelera a oxidação dos tecidos no momento da análise mesmo com uso de antioxidantes e frio.

O uso de gemas dormentes é uma prática já realizada por outros pesquisadores, entre eles Schaefer (1982) e Hudina et al. (1996), com bons resultados, pois nesse período os tecidos dormentes apresentam alta concentração de proteína e baixa flutuação metabólica, facilitando a extração enzimática e diminuindo os danos da oxidação.

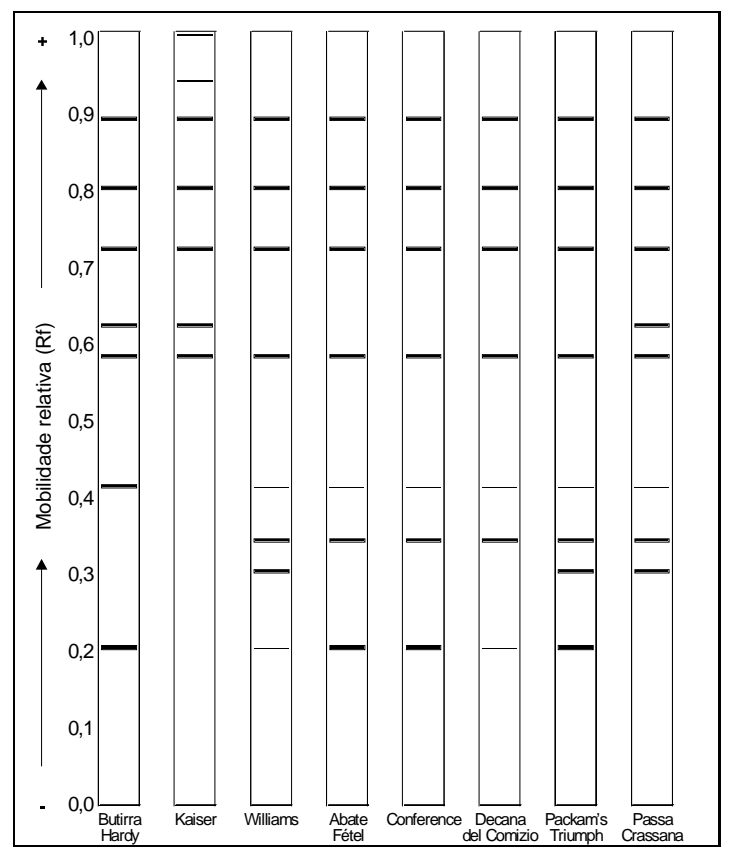

FIG. 3. Padrão isoenzimático da peroxidase obtido da casca de ramos de oito genótipos de pereira auto-radicadas. Bolonha, Itália, 1998.
Os resultados obtidos com a enzima esterase (E.C.3.1.1.2) nas gemas floríferas, folhas, casca dos ramos e folhas das plantas in vitro, conforme pode ser visualizado nas Figs. 5 a 8, permitiram diferenciar todos os genótipos utilizados, ou seja, existe um polimorfismo suficiente para identificar todas as cultivares estudadas, independentemente dos tecidos utilizados. Esses resultados diferem dos obtidos por Hudina et al. (1996), em que apenas as gemas foram a fonte importante para diferenciar as cultivares de pereira e marmeleiro com base nos zimogramas. Tal fato pode ser atribuído a diferenças na metodologia utilizada neste trabalho.

Para a enzima esterase, foram identificadas as duas formas enzimáticas, alfa e beta, sendo a alfa de cor cinza-escuro e a beta de cor violeta, esta última presente de forma mais acentuada nas gemas floríferas dormentes.

Esses resultados indicam que as enzimas peroxidase e esterase podem ser utilizadas para diferenciação varietal de pereiras, mediante técnicas

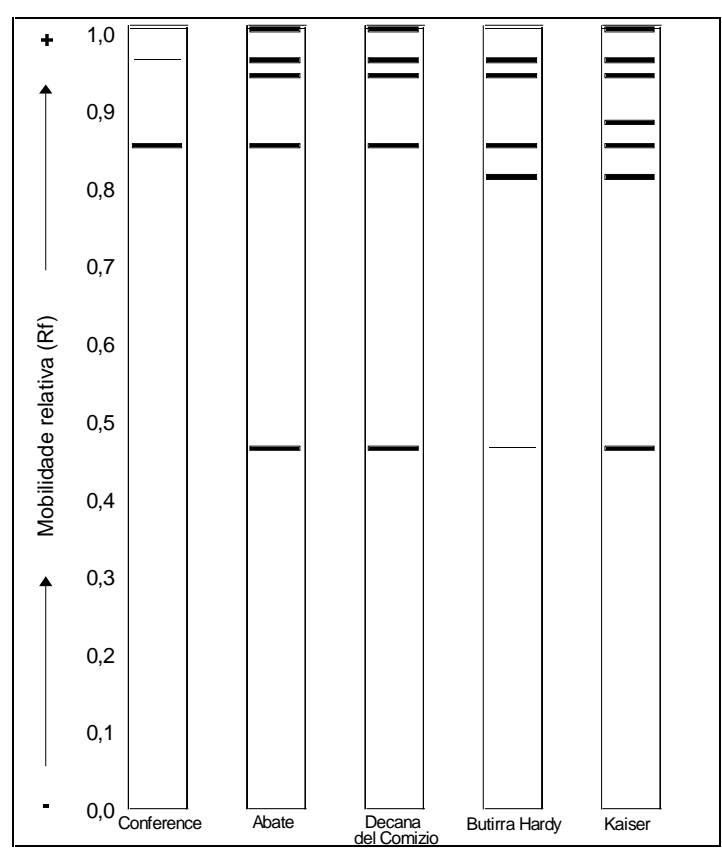

FIG. 4. Padrão isoenzimático da peroxidase obtido de folhas de cinco genótipos de pereira in vitro. Bolonha, Itália, 1998. 


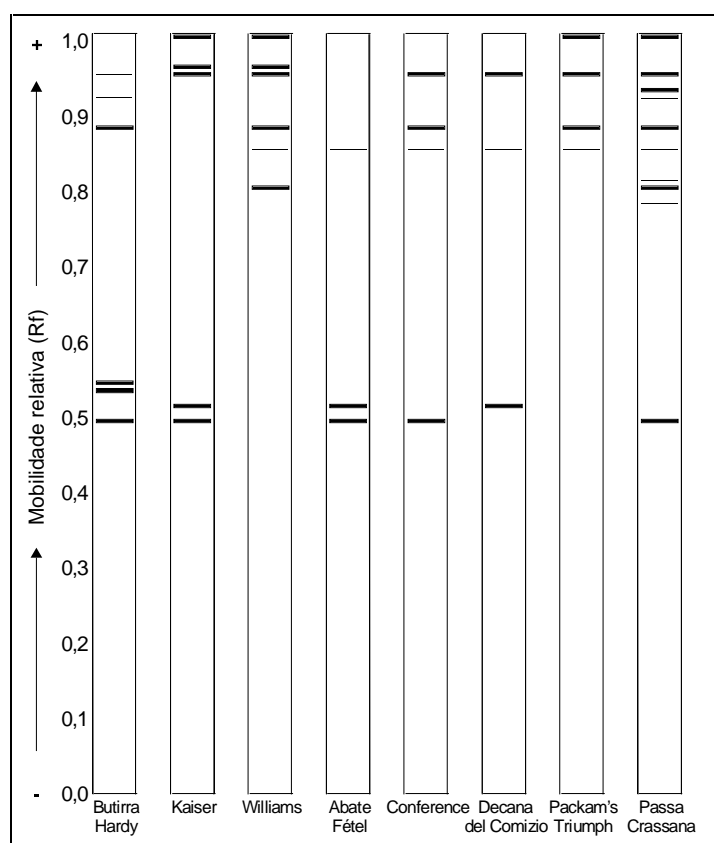

FIG. 5. Padrão isoenzimático da esterase obtido nas folhas de oito genótipos de pereira autoradicadas. Bolonha, Itália, 1998.

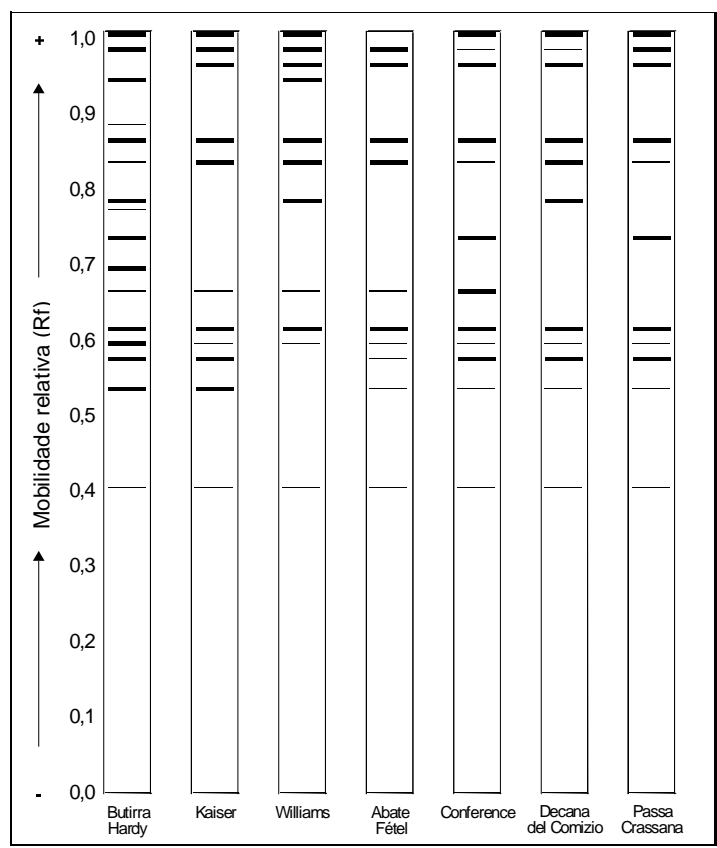

FIG. 6. Padrão isoenzimático da esterase obtido das gemas floríferas dormentes de sete genótipos de pereira auto-radicadas. Bolonha, Itália, 1998.

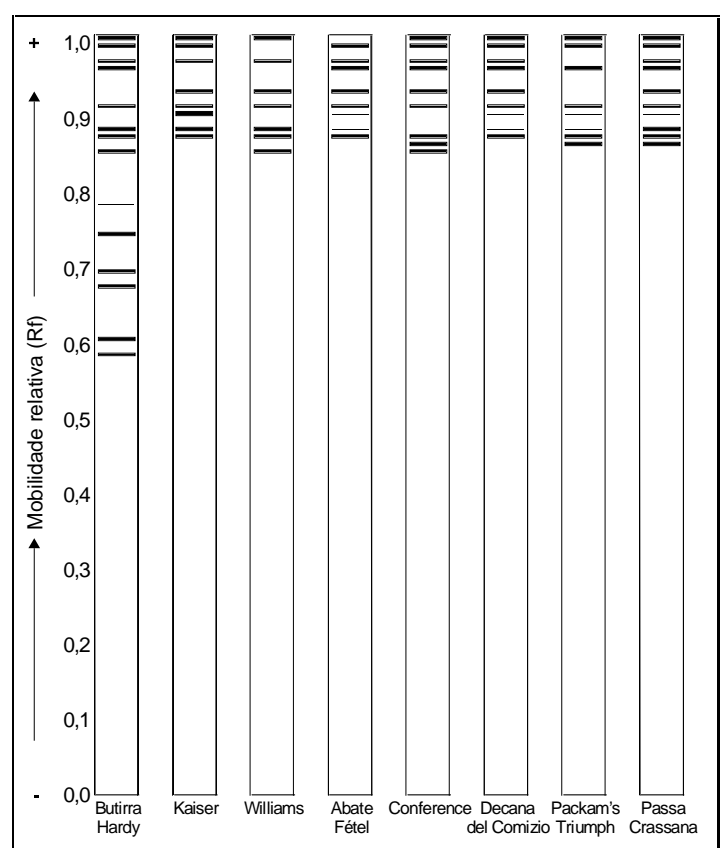

FIG. 7. Padrão isoenzimático da esterase obtido da casca de ramos de oito genótipos de pereira auto-radicadas. Bolonha, Itália, 1998.

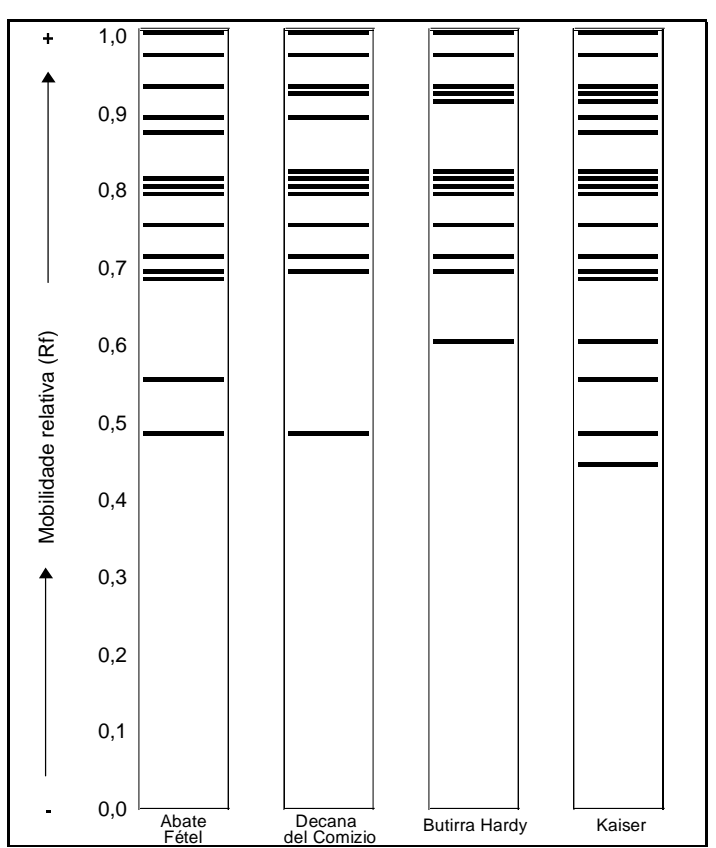

FIG. 8. Padrão isoenzimático da esterase obtido de folhas de cinco genótipos de pereira in vitro. Bolonha, Itália, 1998.

Pesq. agropec. bras., Brasília, v.35, n.7, p.1427-1432, jul. 2000 
eletroforéticas, pois os tecidos apresentam uma elevada fonte de variabilidade genética, principalmente quando se utiliza gemas floríferas dormentes.

Os piores resultados foram obtidos com os zimogramas das folhas das plantas de campo, que, além de apresentarem número menor de bandas eletroforéticas, possuem elevada quantidade de fenóis que compromete a qualidade do extrato enzimático e acelera a oxidação dos tecidos.

\section{CONCLUSÕES}

1. O sistema enzimático $\beta$-glucosidase (E.C.3.2.1.21) não é polimórfico na pereira.

2. Os sistemas de enzimas esterase (E.C.3.1.1.2) e peroxidase (E.C.1.11.1.7) apresentam elevado polimorfismo na pereira.

3. As gemas dormentes apresentam formas isoenzimáticas da peroxidase e esterase que permitem diferenciar todos os genótipos utilizados.

4. Com a enzima esterase é possível diferenciar todos os genótipos analisados, independentemente dos tecidos utilizados.

\section{REFERÊNCIAS}

ANAGNOSTAKIS, S.L. Peroxidase allozyme phenotypes in Castanea and their segregation among progeny. HortScience, Alexandria, v.26, p.1424, 1991.

CEREZO, M.; SOCIAS, R. Isoenzymatic variability in pear pollen. Acta Horticulturae, Wageningen, v.25, p.111-118, 1989.

DALEY, L.S.; MENENDEZ, R.A.; STEBBINS, R.L. Identification of red-fruted pears by fourth derivate spectroscopy of intacta lamina. Journal of Environmental Horticulture, Washington, v.1, p.25-28, 1987

DURHAN, R.E.; MOORE, G.A.; SHERMAN, W.B. Isoenzyme banding patterns and their usefulness as genetic markers in peach. American Society for Horticultural Science Journal, Alexandria, v.112, n.6, p.1013-1018, 1987.

HUDINA, M.; STAMPAR, F.; VIRSCEK-MARN, M.; SMOLE, J. Identification of pear (Pyrus communis L.) and quince (Cydonia oblonga Mill.) cultivars based on isoenzyme variability in various tissues. University of Ljubljana Biotechnical Faculty Research Reports, Ljubljana, v.67, p.173182,1996
IBANEZ, M.A.; DI RENZO, M.A.; POVERENE, M.M. Isoenzyme diversity among and within peach groups: freestone, clingstone and nectarines. Scientia Horticulturae, Amsterdam, v.53, p.281288, 1993

MANGANARIS, A.G.; ALSTON, F.H. Peroxidase isoenzyme genes in the identification of apple cultivars and Malus species. Journal of Horticultural Science, Ashford, v.68, n.5, p.775781,1993

MENENDEZ, R.A.; DALEY, L.S. Characterization of Pyrus species and cultivars using gradient polyacrylamide gel electrophoresis. Journal of Environmental Horticulture, Washington, n.2, p.56-60, 1986

SANTAMOUR JUNIOR, F.S.; DEMUTH, P Identification of callery pear cultivars by peroxidase patterns. Journal of Heredity, New York, v.71, p.447-449, 1980.

SCANDALIOS, J.G. Genetic control of multiple molecular forms of enzymes in plants: a review. Biochemical Genetics, New York, v.3, p.37-79, 1969.

SCHAEFER, H. Extraction of proteins and enzymes from fruit tree tissues. Gartenbauwissenschaft, Stuttgart, v.47, n.3, p.135-141, 1982.

STUBER, C.W.; GOODMAN, M.M.; JOHNSON, F.M. Genetic control and racial variation of $\beta$-glucosidase isoenzymes in maize (Zea mays L.). Biochemical Genetics, New York, v.15, n.3/4, p.383-394, 1977.

TORRES, A.M.; BERG, B.O. Fruit and leaf isoenzymes as genetic markers in avocado. American Society for Horticultural Science Journal, Alexandria, v.105, n.4, p.614-619, 1980.

VALLEJOS, C.E. Enzyme activity staining. In: TANKSLEY, S.D.; ORTON, T.J. (Ed.). Isoenzymes in plant genetics and breeding. Amsterdam : Elsevier, 1983. part A, p.469-516.

VINTERHALTER, D.V.; JAMES, D.J. The use of peroxidase polymorphism in the identification of apple scion cultivars. Scientia Horticulturae, Amsterdam, v.18, p.253-261, 1986a.

VINTERHALTER, D.V.; JAMES, D.J. The use of peroxidase polymorphism in the identification of Malling and Malling Merton apple rootstocks. Journal of Horticultural Science, Ashford, v.61, n.2, p.147-152, 1986b.

WEEDEN, N.F.; LAMB, R.C. Identification of apple cultivars by isoenzyme phenotypes. Journal of Horticultural Science, Ashford, n.110, p.509-515, 1985. 